\title{
Assessment of Future Remnant Liver Function Using Hepatobiliary Scintigraphy in Patients Undergoing Major Liver Resection
}

\author{
Wilmar de Graaf • Krijn P. van Lienden • Sander Dinant • Joris J. T. H. Roelofs • \\ Olivier R. C. Busch • Dirk J. Gouma • Roelof J. Bennink • Thomas M. van Gulik
}

Received: 24 August 2009 /Accepted: 26 October 2009 /Published online: 24 November 2009

(C) The Author(s) 2009. This article is published with open access at Springerlink.com

\begin{abstract}
Background ${ }^{99 \mathrm{~m}}$ Tc-mebrofenin hepatobiliary scintigraphy (HBS) was used as a quantitative method to evaluate liver function. The aim of this study was to compare future remnant liver function assessed by ${ }^{99 \mathrm{~m}} \mathrm{Tc}-\mathrm{mebrofenin}$ hepatobiliary scintigraphy with future remnant liver volume in the prediction of liver failure after major liver resection.

Methods Computed tomography (CT) volumetry and ${ }^{99 \mathrm{~m}} \mathrm{Tc}-$ mebrofenin hepatobiliary scintigraphy were performed prior to major resection in 55 high-risk patients, including 30 patients with parenchymal liver disease. Liver volume was expressed as percentage of total liver volume or as standardized future remnant liver volume. Receiver operating characteristic (ROC) curve analysis was performed to identify a cutoff value for future remnant liver function in predicting postoperative liver failure.

Results Postoperative liver failure occurred in nine patients. A liver function cutoff value of $2.69 \% / \mathrm{min} / \mathrm{m}^{2}$ was calculated by ROC curve analysis. ${ }^{99 \mathrm{~m}} \mathrm{Tc}-\mathrm{meb}$ rofenin hepatobiliary scintigraphy demonstrated better sensitivity, specificity, and positive and negative predictive value compared to future remnant liver volume. Using ${ }^{99 \mathrm{~m}} \mathrm{Tc}-\mathrm{meb}$ rofenin hepatobiliary scintigraphy, one cutoff value suffices in both compromised and noncompromised patients.

Conclusion Preoperative ${ }^{99 \mathrm{~m}} \mathrm{Tc}-\mathrm{mebrofenin}$ hepatobiliary scintigraphy is a valuable technique to estimate the risk of postoperative liver failure. Especially in patients with uncertain quality of the liver parenchyma, ${ }^{99 \mathrm{~m}} \mathrm{Tc}-\mathrm{meb}$ rofenin HBS proved of more value than CT volumetry.
\end{abstract}

Presented at the European Surgical Association (ESA), annual meeting, Dublin 2007.

W. de Graaf • S. Dinant • O. R. C. Busch • D. J. Gouma •

T. M. van Gulik $(\bowtie)$

Department of Surgery, Academic Medical Center,

P.O. Box 22700, 1100 DE Amsterdam, The Netherlands

e-mail: t.m.vangulik@amc.uva.nl

K. P. van Lienden

Department of Radiology, Academic Medical Center,

Amsterdam, The Netherlands

J. J. T. H. Roelofs

Department of Pathology, Academic Medical Center,

Amsterdam, The Netherlands

R. J. Bennink

Department of Nuclear Medicine, Academic Medical Center,

Amsterdam, The Netherlands
Keywords Hepatectomy - Liver failure - Liver function . Liver volume $\cdot$ Mebrofenin $\cdot$ CT volumetry

\section{Introduction}

Major liver resection may result in a small postoperative remnant liver, thereby increasing the risk of postoperative liver failure, especially in patients with parenchymal disease. ${ }^{1}$ Posthepatectomy liver failure is the most frequent cause of mortality after liver resection. Although the causes of liver failure are multifactorial, insufficient postoperative remnant liver function is one of the main contributing factors.

Preoperative computed tomography (CT) volumetry, in which liver volume is used as an indirect measurement of liver function, is widely used to identify patients who 
should be excluded from a planned liver resection or to select patients who will benefit from preoperative portal vein embolization (PVE). ${ }^{1-5}$ Future remnant liver (FRL) volume (FRL-V) is expressed as a percentage of total liver volume $(\% \mathrm{FRL}-\mathrm{V}),{ }^{3}$ or as standardized FRL (sFRL), in which FRL-V is calculated as percentage of total liver volume based on body surface area (BSA). ${ }^{4,6}$ sFRL recognizes patient characteristics (body weight/BSA) but has only been validated in patients with healthy livers. In patients with a normal liver parenchyma, an \%FRL-V or sFRL larger than $25-30 \%$ of total preoperative liver volume is considered sufficient for a safe resection, ${ }^{3,4,7-9}$ whereas in patients with a compromised liver (e.g., fibrosis, steatosis, or cholestasis), a \%FRL-V or sFRL of more than $40 \%$ is preferred. ${ }^{10}$ The separate cutoff values indicate the necessity to asses the quality of the liver parenchyma in order to perform an accurate and safe preoperative risk analysis using CT volumetry. Preoperative liver biopsy is currently the most reliable method to assess the quality of the liver parenchyma. Biopsies are not routinely performed due the potential unequal distribution of parenchymal damage $^{11}$ and the risk of complications. ${ }^{12,13}$ As a result, the quality of the liver parenchyma frequently remains unknown, rendering preoperative risk analysis by $\mathrm{CT}$ volumetry less reliable.

For accurate preoperative risk analysis, additional tests of liver function are required. Dynamic ${ }^{99 \mathrm{~m}} \mathrm{Tc}-$ mebrofenin hepatobiliary scintigraphy (HBS) was developed as a quantitative method for evaluating total and regional liver function, including FRL function. ${ }^{14,15}$ The hepatic uptake of ${ }^{99 \mathrm{~m}} \mathrm{Tc}$-mebrofenin is similar to the uptake of organic anions such as bilirubin. ${ }^{16}$ After the hepatic uptake, ${ }^{99 \mathrm{~m}} \mathrm{Tc}$ mefrofenin is excreted into the bile canaliculi without undergoing biotransformation during its transport through the hepatocytes. Although ${ }^{99 \mathrm{~m}} \mathrm{Tc}$-mebrofenin is not metabolized, the uptake and intracellular transit are similar to various endogenous and exogenous substances including bilirubin, hormones, drugs, and toxins. In a recent publication, we demonstrated that ${ }^{99 \mathrm{~m}} \mathrm{Tc}-$ mebrofenin HBS has potential to predict postoperative liver failure in a patient population including both minor and major liver resections. ${ }^{17}$ The advantage of using ${ }^{99 \mathrm{~m}} \mathrm{Tc}-\mathrm{meb} r o f e n i n$ HBS is the fact that the same cutoff value can be used for both patients with a compromised or normal liver parenchyma, which makes the test applicable in patients with an uncertain quality of the liver parenchyma. However, it remains uncertain if ${ }^{99 \mathrm{~m}} \mathrm{Tc}-$-mebrofenin HBS is sufficiently accurate to predict liver failure in a population containing high-risk patients requiring major hepatic resection. This study compares preoperative FRL function assessed by HBS with FRL-V, expressed as \%FRL-V and SFRL, in the prediction of postoperative liver failure after major liver resection in high-risk patients.

\section{Patients and Methods}

\section{Patients}

Between May 2000 and November 2006, 213 patients underwent a partial hepatectomy. Of all patients undergoing major liver resection (three or more Couinaud segments), both CT volumetry and HBS were preoperatively performed in 71 patients. Sixteen patients were excluded from the study because of preoperative PVE $(n=15)$ or partial portal vein thrombosis $(n=1)$ in the time period between HBS and CT volumetry. Hence, a group of 55 patients was retrospectively analyzed with the approval of our Institutional Review Board with waiver of informed consent. Table 1 summarizes the types of resection performed. Patients with a preoperative suspicion of hilar cholangiocarcinoma underwent an (extended) hemihepatectomy combined with hilar resection and caudate lobe resection. In cholestatic patients, preoperative biliary drainage was performed more than 6 weeks prior to surgery using endoscopic retrograde cholangiopancreatography or percutaneous transhepatic drainage.

Pre- and perioperative factors associated with postoperative morbidity and mortality were analyzed (Table 5). Histopathology of the resection specimen was assessed by an experienced pathologist taking into account features of cholestasis, steatosis, fibrosis, and chronic inflammation.

Postoperative complications were recorded according to the modified classification of surgical complications proposed by Dindo et al. ${ }^{18}$ In-hospital complications were recorded as well as complications requiring hospital readmission within 3 months related to the operation. Minor complications included grade 1 and grade 2 complications. Major complications were defined as grade 3 and severe compli-
Table 1 Types of Liver Resection with the Corresponding Weight of the Resection Specimen

\begin{tabular}{lccl}
\hline procedure & Number of patients & Percentage & Weight resection specimen (g) \\
\hline Extended right hemihepatectomy & 14 & 25.5 & $975 \pm 247$ \\
Right hemihepatectomy & 26 & 47.2 & $936 \pm 396$ \\
Extended left hemihepatectomy & 1 & 1.8 & 443 \\
Left hemihepatectomy & 14 & 25.5 & $348 \pm 120$ \\
Total & 55 & 100.0 & \\
\hline
\end{tabular}


cations as grade 4 and grade 5 complications. Liver failure was defined as bilirubin plasma levels $>50 \mu \mathrm{mol} / 1$ and/or prothrombin time index $<50 \%,{ }^{19}$ elevated plasma ammonia levels combined with signs of hepatic encephalopathy and/or hepatorenal syndrome, requiring intensive care treatment.

\section{Surgical Technique}

Surgery was performed under low central venous pressure $\left(<4 \mathrm{~cm} \mathrm{H}_{2} \mathrm{O}\right)$. Liver parenchymal transsection was performed using Cavitron Ultrasonic Surgical Aspirator (Valley Lab, Boulder, CO, USA). Pringle maneuver was applied in 29 patients (54\%) to reduce intraoperative blood loss, with a mean ischemic period of $37 \pm 13 \mathrm{~min}$. Intermittent clamping was applied in eight patients (15\%).

\section{Scintigraphic Imaging and Data Acquisition}

HBS was performed using ${ }^{99 \mathrm{~m}} \mathrm{Tc}$-mebrofenin as previously described. ${ }^{14,15}$ Briefly, after injection of $85 \mathrm{MBq}$ of ${ }^{99 \mathrm{~m}} \mathrm{Tc}-$ mebrofenin (Bridatec; GE-Amersham Health), dynamic images were obtained with a $\gamma$-camera (Diacam, Siemens, Milwaukee, WI, USA) for $60 \mathrm{~min}$. During the first $10 \mathrm{~min}$, 60 frames of $10 \mathrm{~s}$ were acquired (liver uptake phase) followed by 50 frames of $1 \mathrm{~min}$ (liver excretion phase). Total hepatic ${ }^{99 \mathrm{~m}} \mathrm{Tc}-\mathrm{mebrofenin}$ uptake rate was calculated as described by Ekman et al. ${ }^{20}$ On preoperative HBS, regions of interest (ROIs) were drawn around the total liver, the heart (serving as blood pool), and the total field of view. From these ROIs, three time-activity curves were generated (Fig. 1). Total hepatic ${ }^{99 \mathrm{~m}} \mathrm{Tc}-$ mebrofenin uptake rate, representing total liver function (TL-F), was calculated as percent per minute: (\%/min) (of the injected dose) based on these three parameters. Calculations of hepatic ${ }^{99 \mathrm{~m}} \mathrm{Tc}$-mebrofenin uptake rate were performed using measured values obtained between 150 and $350 \mathrm{~s}$ postinjection to ensure that hepatic uptake calculations were performed during a phase of homogenous distribution of the agent in the blood pool, before occurrence of the rapid phase of hepatic excretion. To compensate for differences in individual metabolic requirements, TL-F was divided by BSA and expressed as percent per minute per square meter: $\left(\% / \mathrm{min} / \mathrm{m}^{2}\right)$. For determination of FRL uptake, a ROI was drawn around the FRL by two independent investigators, blinded for the results, according to the performed resection, and interobserver variation was calculated. The round ligament was used as the border between segment three and four. Cantlie's line, projected on the liver surface as a plane between the middle of the gallbladder fossa (visible in the late phase of the scintigraphy) and the inferior caval vein, was used as a border between the right and left liver lobes. In addition, the anterior projection of the liver on the CT volumetry was used as a guideline for delineating the FRL on the HBS images
(Fig. 1). FRL uptake function (FRL-F) was calculated by dividing counts within the delineated FRL by the total liver counts and multiplying this factor with total liver ${ }^{99 \mathrm{~m}} \mathrm{Tc}-$ mebrofenin uptake (TL-F) and expressed as percent per minute per square meter: $\left(\% / \mathrm{min} / \mathrm{m}^{2}\right)$. In 33 patients, a postoperative HBS was performed within 3 days after the operation to measure actual remnant liver function.

\section{CT Volumetry}

Contrast-enhanced CT scans were generated with a helical scanner (Philips, Eindhoven, The Netherlands). Manual 3D reconstructions of the liver were made using reconstructed 5 -mm-thick axial slices from $2-3-\mathrm{mm}$ original slices. The total liver as well as tumor(s) and the FRL were manually outlined using portal and hepatic veins as landmarks for segmental division. Integrated software (Mx-View 3.52, Philips Medical Systems) was used to calculate total liver volume (TL-V), tumor volume (TV), and FRL-V. All delineations were made by an experienced radiologist. FRL-V was expressed as percentage of TL-V using the formula:

$\% \mathrm{FRL}-\mathrm{V}=\frac{\mathrm{FRL}-\mathrm{V}}{(\mathrm{TLV}-\mathrm{TV})} \times 100 \%$

The nontumorous total liver volume $\left({ }^{\mathrm{NT}} \mathrm{TL}-\mathrm{V}\right)$ was calculated by excluding the tumor volume from the TL-V.

\section{Standardized FRL Measurements}

FRL-V was determined using CT volumetry, while total liver volume ( $\left.{ }^{\text {cal }} \mathrm{TL}-\mathrm{V}\right)$ was calculated using a formula based on $\mathrm{BSA}^{6}$ : ${ }^{\text {cal }} \mathrm{TL}-\mathrm{V}=-794.41+1,267.28 \times \mathrm{BSA}^{2}$ $(\mathrm{BSA}=\sqrt{\text { height }(\mathrm{cm}) \times \text { weight }}(\mathrm{kg}) / 3,600)$.

The sFRL was calculated as the percentage between FRL-V and calculated TL-V.

\section{Preoperative Risk Assessment}

Receiver operator characteristics (ROC) curve analysis was used to calculate the optimal cutoff value for FRL-F in predicting postoperative liver failure. Cutoff values were determined based on the following assumptions: Firstly, the chance that liver failure would develop while the test result was above the cutoff value needed to be as low as possible. Secondly, a test result below the cutoff value should accurately select high-risk patient who might benefit from PVE. Based on literature, cutoff values for \%FRL-V and sFRL were set at $30 \%$ for patients with normal liver parenchyma ${ }^{9}$ and $40 \%$ for patients with a compromised liver. ${ }^{10}$ Positive predictive values (PPV), negative predictive values (NPV), as well as sensitivity and specificity were determined for each method. 
Figure 1 An example is shown of summed HBS images from 150-300 s after i.v. injection of ${ }^{99 \mathrm{~m}} \mathrm{Tc}$-mebrofenin (a). A ROI is drawn around the entire liver (red line) and around the mediastinum (blood pool; yellow line). A third ROI is drawn around the future remnant liver (green line). A blood pool corrected liver-uptake time-activity curve is shown in $\mathbf{b}$. The hepatic ${ }^{99 \mathrm{~m}} \mathrm{Tc}$-mebrofenin uptake is calculated as an increase of ${ }^{99 \mathrm{~m}} \mathrm{Tc}-\mathrm{meb}$ ofenin uptake $(y$ axis) per minute over a time period of $200 \mathrm{~s}$ ( $x$-axis). $\mathbf{c}$ The use of the anterior projection of the liver on the CT volumetry image as a guideline for delineating the FRL on the HBS image (d).
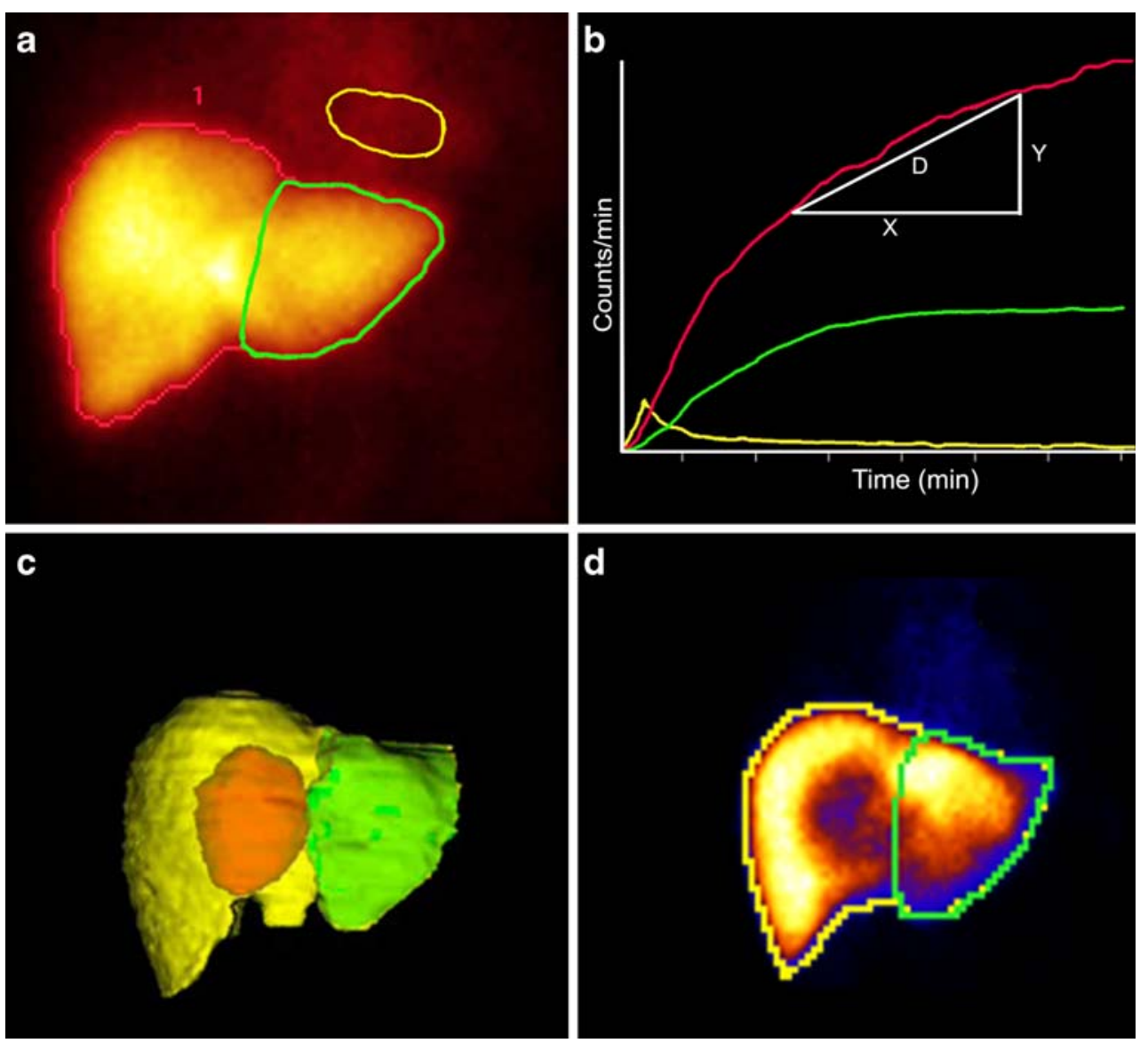

\section{Statistical Analysis}

Statistical analysis was performed with GraphPad Prism (GraphPad Software, San Diego, CA, USA) and Statistical Package for Social Sciences (SPSS 12.02, Chicago, IL, USA). ROC curve analysis was used to identify a cutoff value for FRL-F in predicting postoperative liver failure. Univariate analysis of preoperative and intraoperative variables was performed by the independent $t$ test for continuous parameters and by Pearson's 2 tests and Fisher's exact test for categorical data. Correlation between variables was tested using the Pearson correlation coefficient $r$. Continuous data were compared by independent sample $t$ test and expressed as mean \pm standard deviation. All statistical tests were twotailed, and differences were considered significant at a $P$ value of $\leq 0.05$.

\section{Results}

\section{Patient Characteristics}

CT volumetry and ${ }^{99 \mathrm{~m}}$ Tc-mebrofenin HBS were performed in 55 patients (male 26, female 29, mean age $59 \pm 13$ years). Indications for liver resection are shown in Table 2 . Thirty patients were diagnosed with a compromised liver parenchyma based on the histopathological evaluation of the resection specimen by an experienced pathologist, including cirrhosis $(n=2)$, severe fibrosis $(n=3)$, steatosis $(>30 \%$ of the hepatocytes affected; $n=3)$, severe cholestasis $(n=8)$, chronic inflammation $(n=3)$, or a combination of these diseases $(n=11)$.

\section{Liver Function and Liver Volume}

TL-F was significantly lower in patients with parenchymal liver disease $\left(7.4 \pm 1.4 \% / \mathrm{min} / \mathrm{m}^{2}\right)$ as compared to patients with healthy liver parenchyma $\left(8.5 \pm 1.7 \% / \mathrm{min} / \mathrm{m}^{2}, P=0.007\right)$. ${ }^{\mathrm{NT}} \mathrm{TL}-\mathrm{V}$ was significantly larger in patients with compromised livers $\left(1,037.1 \pm 208.0\right.$ vs. $877.0 \pm 143.3 \mathrm{~mL} / \mathrm{m}^{2}, P=$ 0.001; Fig. 2).

Table 2 Indications for Liver Resection

\section{Liver metastasis $(n=14)$}

Hilar cholangiocarcinoma $(n=19)$

Intrahepatic cholangiocarcinoma $(n=3)$

Hepatocellular carcinoma $(n=6)$

Benign biliary strictures $(n=7)$

Benign lesions $(n=6)$ 


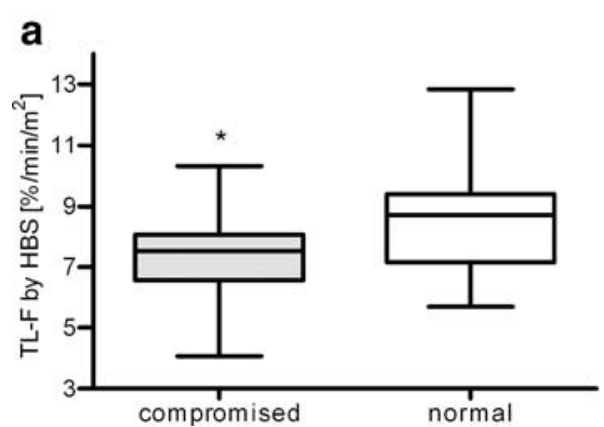

Figure 2 Total hepatic ${ }^{99 \mathrm{~m}}$ Tc-mebrofenin uptake according to parenchymal status. Patients with parenchymal liver disease had significantly less liver (uptake) function (gray box, $7.4 \pm 1.4 \% / \mathrm{min} / \mathrm{m}^{2}$ ) as compared to patients with healthy liver parenchyma (white box, $8.5 \pm$

According to the type of resection performed, FRL-F was calculated for each individual patient by two independent observers. The interobserver agreement was excellent (Pearson $r=0.97$ ), and Bland-Altman analysis revealed almost no bias between the two observers (mean bias of 0.00058 with $95 \%$ limit of agreement between -0.835 and 0.836 ). Preoperative FRL-F correlated strongly with actual postoperative remnant liver function determined within 3 days after surgery (Pearson $r=0.83, P<0.0001$; Fig. 3). Liver weight of the resection specimen revealed a strong correlation (Pearson $r=0.91, P<$ 0.0001 ) with its volume assessed by CT volumetry, confirming the CT measurements.

FRL-V correlated well with FRL-F (Pearson $r=0.72, P=$ 0.0001 ) in patients with normal livers. In contrast, patients with a compromised liver demonstrated only a moderate correlation between FRL-V and FRL-F (Pearson $r=0.61, P<$ $0.0003)$. The slope coefficient of the linear regression curve indicated that FRL-V is associated with significantly $(P=$ 0.0015 , analysis of covariance test) reduced FRL-F in compromised livers as compared to normal livers (Fig. 4).

\section{Postoperative Complications}

In 42 of the $55(76 \%)$ patients, one or more complications occurred following liver resection (Table 3). Minor and major

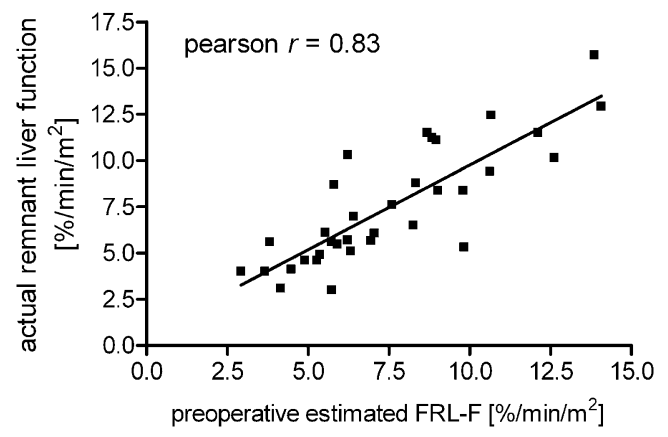

Figure 3 Scatter plot showing the correlation between preoperative FRL-F and actual postoperative remnant liver function measured within 3 days after surgery (33 patients, Pearson $r=0.81, P<0.0001$ ).

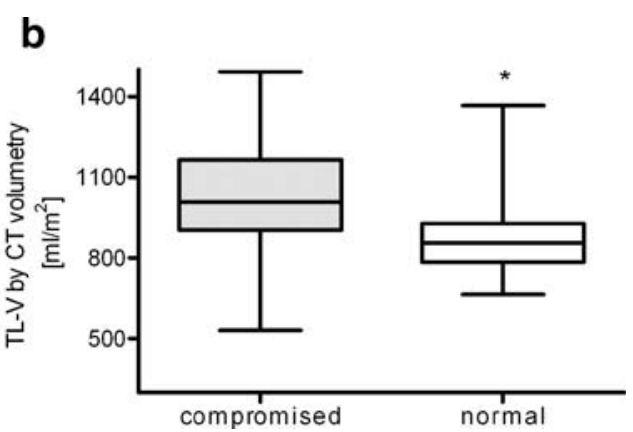

$1.7 \% / \mathrm{min} / \mathrm{m}^{2}, \quad P=0.007$; a). Total liver volume: ( $\left.{ }^{\mathrm{NT}} \mathrm{TL}-\mathrm{V}\right)$ was significantly higher in patients with compromised livers $(1,037.1 \pm$ 208.0 vs. $\left.877.0 \pm 143.3 \mathrm{~mL} / \mathrm{m}^{2}, P=0.001 ; \mathbf{b}\right)$.

complications were evident in 14 patients $(25 \%)$ and 13 patients $(24 \%)$, respectively. Fifteen patients $(27 \%)$ developed severe complications requiring ICU treatment, and the mortality rate was $15 \%$. Patients with severe complications had significantly lower FRL-F as compared to patients with no complications $(P=0.0043)$, minor complications $(P=$ $0.0028)$, or major complications $(P=0.0046)$

Nine patients $(16 \%)$ developed postoperative liver failure, of which eight patients died. In four patients, liver failure was evident within 1 week after the operation. Five patients developed liver failure within several weeks after the operation in conjunction with signs of sepsis. Evidence of a compromised liver was seen in eight patients (89\%), and in seven patients, an extended hemihepatectomy had been performed. The FRL-F was significantly lower in patients with postoperative liver failure ( $2.18 \%$ vs. $\left.4.32 \% / \mathrm{min} / \mathrm{m}^{2}, P=0.0001\right)$.

Preoperative and Intraoperative Parameters Associated with Liver Failure

Univariate analysis revealed that elderly patients $(P=0.043)$, small \%FRL-V $(P=0.024)$, small sFRL $(P=0.012)$, small

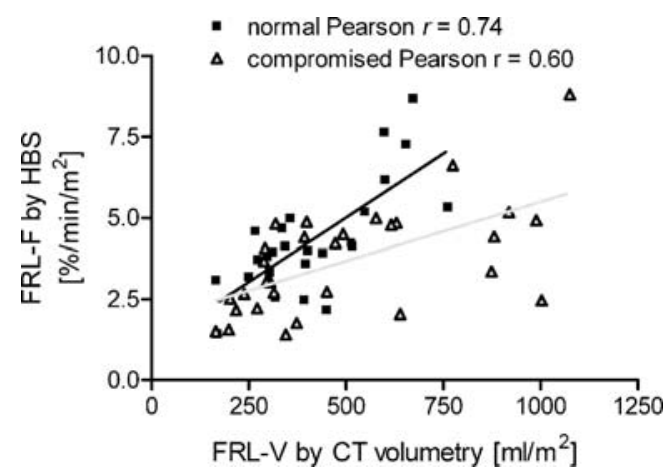

Figure 4 Scatter plot showing the correlation between FRL-F and FRL-V. In patients with normal livers (black line), FRL-V correlated well with FRL-F (Pearson $r=0.71, P=0.0001$ ). Patients with compromised livers (gray line) showed a moderate correlation between FRL volume and FRL function (Pearson $r=0.61, P<0.0003$ ). 
Table 3 Postoperative Complications
Grade $0(n=13)$

Grade $1 *(n=5)$

Grade $2 *(n=9)$

Grade $3 \mathrm{a}(n=12)$

Grade $3 \mathrm{~b}(n=1)$

Grade $4 \mathrm{a}(n=5)$

Grade $4 \mathrm{~b}(n=2)$

Grade $5(n=8)$
No complications

Minor complications

Minor complications

Major complications

Major complications

Severe complications

Severe complications

Severe complications
Grade 1 needed no therapy except analgetics, diuretics, anti-emetics, and physiotherapy. Grade 2 complications required pharmacological treatment. Grade 3 complications required surgical, endoscopic, or radiological intervention (grade 3a under local anesthetics, grade 3b under general anesthetics). Grade 4 complications included life-threatening complications requiring ICU management (grade $4 \mathrm{a}$ with single organ dysfunction, grade $4 \mathrm{~b}$ with multi-organ failure). Grade 5 complications resulted in death

*One patient could have multiple grade 1 or 2 complications

FRL-F $(P=0.001)$, resection type $(P=0.001)$, prolonged operating time $(P=0.0018)$, increased blood loss $(P=$ $0.0018)$ during the operation, and the presence of a compromised liver parenchyma $(P=0.024)$ were significantly associated with postoperative liver failure (Table 4). Due to a small sample size in the liver failure group $(n=9)$, no multivariate analysis was performed.

\section{Preoperative Prediction of Postoperative Liver Failure}

ROC analysis revealed that a cutoff value for FRL-F of $2.69 \% / \mathrm{min} / \mathrm{m}^{2}$ was able to identify patients who developed postoperative liver failure with a sensitivity of $89 \%$ and a specificity of $87 \%$ (Fig. 5). The risk of postoperative liver failure in patients with a FRL-F above $2.69 \% / \mathrm{min} / \mathrm{m}^{2}$ was $2.4 \%$ (with a NPV of $97.6 \%$ and a likelihood ratio for a negative test result of 0.12 ). The PPV was $57.1 \%$ with a likelihood ratio for a positive test result of 6.8. Table 5 summarizes the sensitivity, specificity, PPV, NPV, and likelihood ratios of the different tests. For an accurate use of \%FRL-V and sFRL, two cutoff values were used, and patients were divided in patients with a normal liver parenchyma and patients with a compromised liver parenchyma based on the histopathology of the resection specimen. Using ${ }^{99 \mathrm{~m}} \mathrm{Tc}$-mebrofenin HBS, one cutoff value sufficed in both compromised and noncompromised patients. Assuming that, of all the patients, the quality of the liver parenchyma was preoperatively known, sensitivity, specificity, and positive and negative predictive values were still better for FRL-F compared to \%FRL-V and sFRL (Table 5).

\section{Discussion}

Accurate measurement of liver function before liver resection is crucial in the assessment of resectability, especially in patients requiring major liver resection. The availability of preoperative PVE to induce hypertrophy of the FRL has further increased the importance of preoperative assessment of regional hepatic function. ${ }^{7,21-24}$ In the present study, dynamic planar ${ }^{99 \mathrm{~m}} \mathrm{Tc}-\mathrm{mebrofenin}$ HBS was used to measure liver function. This technique can be implemented in every hospital with a nuclear medicine department, is easy to perform, and has a small interobserver variability. More importantly, preoperative estimated function of the future remnant liver (FRL-F) correlates strongly with actual postoperative liver function, ${ }^{14}$ indicating that dynamic planar ${ }^{99 \mathrm{~m}} \mathrm{Tc}-\mathrm{mebrofenin}$ HBS is an accurate method to assess FRL-F.

In this study, we compared FRL-F measured by ${ }^{99 \mathrm{~m}} \mathrm{Tc}$ mebrofenin HBS with two parameters based on CT volumetry, which are widely accepted parameters to determine the possible extent of resection. ${ }^{1-5}$ Patients with a compromised liver had a significantly lower liver function compared to patients with normal liver parenchyma, whereas their liver volume was significantly larger. FRL$\mathrm{V}$ showed a strong relation with FRL-F in patients with normal liver parenchyma. In contrast, FRL-V and FRL-F only moderately correlated in patients with compromised liver parenchyma in whom FRL-V was associated with reduced FRL-F. The impact of different parenchymal diseases such as steatosis, cholestasis, and fibrosis on liver function and liver volume is unknown and may vary among individuals. In addition, parenchymal damage is often not equally distributed, ${ }^{11}$ which can partially explain the moderate correlation between FRL-V and FRL-F in patients with compromised livers. ROC curve analysis yielded an FRL-F cutoff of $2.69 \% / \mathrm{min} / \mathrm{m}^{2}$ for the prediction of postoperative liver failure. This cutoff value is comparable to the cutoff value determined in a patient population including both minor and major resections. ${ }^{17}$

A reliable preoperative test should primarily establish whether patients with a FRL-F above the critical threshold

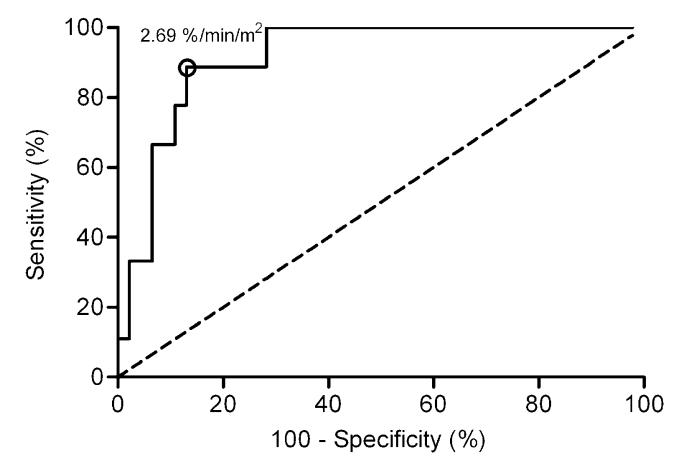

Figure 5 Receiver operator characteristic curve analysis of FRL-F in the prediction of liver failure. A cutoff value for FRL-F of $2.69 \% / \mathrm{min} /$ $\mathrm{m}^{2}$ identified patients with a significant risk of developing postoperative liver failure (area under the curve $=0.916 ; 95 \%$ confidence interval 0.837-0.994). 
Table 4 Comparison of Pre- and Intraoperative Parameters in Patients with or Without Liver Failure

\begin{tabular}{|c|c|c|c|}
\hline & Patients with liver failure $(n=9)$ & Patients without liver failure $(n=46)$ & $P$ value \\
\hline \multicolumn{4}{|l|}{ Demographics } \\
\hline Male/female & $7: 2$ & $19: 27$ & $0.069^{\mathrm{a}}$ \\
\hline Age & $67.1 \pm 6.0(58-67)$ & $57.1 \pm 13.7(18-78)$ & $0.027^{\mathrm{b}}$ \\
\hline BMI & $25.1 \pm 2.1$ & $24.0 \pm 3.6$ & $0.33^{\mathrm{b}}$ \\
\hline \multicolumn{4}{|l|}{ FRL volume } \\
\hline \%FRL-V (\%) & $35.0 \pm 22.0$ & $49.7 \% \pm 17.8$ & $0.013^{\mathrm{b}}$ \\
\hline sFRL (\%) & $35.2 \pm 9.2$ & $49.2 \% \pm 3.6$ & $0.018^{\mathrm{b}}$ \\
\hline FRL-F $\left(\% / \mathrm{min} / \mathrm{m}^{2}\right)$ & $2.2 \pm 0.6$ & $4.3 \% \pm 1.6$ & $0.001^{\mathrm{b}}$ \\
\hline \multicolumn{4}{|l|}{ Comorbidity } \\
\hline Diabetes (yes/no) & $2: 7$ & $5: 41$ & $0.32^{\mathrm{a}}$ \\
\hline Chronic hepatitis (yes/no) & $2: 7$ & $3: 43$ & $0.18^{\mathrm{a}}$ \\
\hline Vascular disease(yes/no) & $3: 6$ & $9: 37$ & $0.39^{\mathrm{a}}$ \\
\hline Compromised liver (yes/no) & $8: 1$ & $22: 24$ & $0.024^{\mathrm{a}}$ \\
\hline \multicolumn{4}{|l|}{ Resection type } \\
\hline Left hemihepatectomy & 1 & 13 & \\
\hline Right hemihepatectomy & 1 & 25 & $0.001^{\mathrm{c}}$ \\
\hline Extended hemihepatectomy & 7 & 8 & \\
\hline \multicolumn{4}{|l|}{ Preoperative laboratory values } \\
\hline AST & $51.4 \pm 19.1$ & $48.2 \pm 32.4$ & $0.24^{\mathrm{b}}$ \\
\hline ALT & $57.9 \pm 27.2$ & $65.6 \pm 65.6$ & $0.55^{\mathrm{b}}$ \\
\hline Bilirubin & $19.9 \pm 14.9$ & $14.2 \pm 12.0$ & $0.20^{\mathrm{b}}$ \\
\hline $\mathrm{AF}$ & $265.2 \pm 204.6$ & $280.1 \pm 260.5$ & $0.76^{\mathrm{b}}$ \\
\hline GGT & $409.9 \pm 272.7$ & $392.7 \pm 605.7$ & $0.13^{\mathrm{b}}$ \\
\hline Albumin & $39.4 \pm 5.8$ & $39.5 \pm 5.9$ & $0.84^{\mathrm{b}}$ \\
\hline Prothrombin time & $13.0 \pm 1.5$ & $13.1 \pm 0.90$ & $0.63^{\mathrm{b}}$ \\
\hline \multicolumn{4}{|l|}{ Intraoperative parameters } \\
\hline Blood loss (mL) & $5,200 \quad \mathrm{cc} \pm 2,673$ & $3,025 \pm 2,464$ & $0.021^{\mathrm{b}}$ \\
\hline Operating time (min) & $507.4 \pm 135.1$ & $382.3 \pm 131$ & $0.011^{\mathrm{b}}$ \\
\hline Pringle maneuver yes/intermittent/no & $3: 2: 3$ & $26: 6: 14$ & $0.62^{\mathrm{c}}$ \\
\hline Pringle time $(\mathrm{min})$ & $35.0 \pm 5.0$ & $36.71 \pm 13.5$ & $0.96^{\mathrm{b}}$ \\
\hline Intermittent total ischemia time ( $\mathrm{min})$ & 40.0 & 47.6 & $0.5^{\mathrm{b}}$ \\
\hline
\end{tabular}

$A S T$ aspartate aminotransferase, $A L T$ alanine aminotransferase, $A F$ alkaline phosphatase, $G G T$ gamma-glutamyltransferase, $B M I$ body mass index

${ }^{a}$ Fisher's exact test

${ }^{\mathrm{b}}$ Mann-Whitney $U$ test

${ }^{c} \chi^{2}$ test

can be safely resected. One patient developed liver failure despite a FRL-F above $2.69 \% / \mathrm{min} / \mathrm{m}^{2}$ (Table 6). This cirrhotic patient developed massive necrosis after left hemihepatectomy, due to an obliterated right hepatic artery and a compromised portal venous system. When CT volumetry would have been used as selection criterion for operation, two patients developed liver failure despite a \% FRL-V of more than $40 \%$ (Table 6). Standardized FRL wrongly predicted a safe resection in three patients (Table 6). Although the formula generally used to calculate TL-V based on BSA is used for all patients, it is derived from patients with normal liver parenchyma. In our study, patients with a compromised liver had significantly larger liver volumes resulting in a relatively larger FRL-V in relation to their BSA. As a consequence, there is an overestimation of liver function in these patients.

Secondly, a preoperative test should be accurate in selecting high-risk patients who might benefit from PVE, without treating patients unnecessarily. Despite having a FRL-F below the critical value of $2.69 \% / \mathrm{min} / \mathrm{m}^{2}, 43 \%$ of these high-risk patients did not develop liver failure. In literature, a similar percentage was reported when using CT volumetry for the prediction of postoperative hepatic dysfunction. ${ }^{8}$ Additional negative predictive factors, in- 
Table 5 Overview of the Sensitivity, Specificity, PPV, NPV as well as likelihood ratio's for FRL-F, \%FRL-V, and sFRL in the Prediction of Postoperative Liver Failure

\begin{tabular}{llll}
\hline Outcome parameter & FRL-F & \%FRL-V & sFRL \\
\hline Cutoff value & $2.69 \% / \mathrm{min} / \mathrm{m}^{2}$ & Normal liver $<30 \%$ & Normal liver $<30 \%$ \\
& & Compromised liver $<40 \%$ & Compromised liver $<40 \%$ \\
Sensitivity & $89 \%$ & $78 \%$ & $67 \%$ \\
Specificity & $87 \%$ & $80 \%$ & $87 \%$ \\
PPV & $57 \%$ & $44 \%$ & $50 \%$ \\
NPV & $98 \%$ & $95 \%$ & $93 \%$ \\
LR+ & 6.8 & 4.0 & 5.1 \\
LR- & 0.12 & 0.19 & 0.38 \\
\hline
\end{tabular}

$F R L$ future remnant liver, \%FRL-V future remnant liver/total liver volume percentage, $P P V$ positive predictive value, $N P V$ negative predictive value, $L R+$ likelihood ratio for positive test result, $L R-$ likelihood ratio for negative test result

cluding high body mass index, significant intraoperative blood loss, and prolonged operating time, were described in patients with hepatic dysfunction, underlining the multifactorial cause of postoperative liver failure. In our study, univariate analysis revealed that, besides small FRL volume and function, increased intraoperative blood loss, prolonged operating time, a compromised liver parenchyma and older age were associated with liver failure. Unfortunately, a multivariate analysis was not possible in our study due to the small number of patients with postoperative liver failure. Cutoff values for the prediction of postoperative complications and hepatic dysfunction have been reported using CT volumetry, ${ }^{3,4,7-9}$ indocyanine green clearance test, ${ }^{25}$ galactose elimination capacity, ${ }^{26}$ and ${ }^{99 \mathrm{~m}} \mathrm{Tc}-\mathrm{GSA}$ scintigraphy. ${ }^{27-30}$ These cutoff values were, however, mostly not based on accurate risk calculations and no or inappropriate multivariate analyses had been performed.

Morbidity and mortality rates reported in our study were high, which is explained by the patients selected for this study. We only included patients undergoing major liver resection of which the majority (55\%) had parenchymal liver disease. A relatively high proportion (39\%) of patients had undergone resection on the suspicion of hilar cholangiocarcinoma, including six patients who had developed postoperative liver failure. These patients require large resections and biliary anastomoses, with increased risk of postoperative morbidity and mortality, reported up to 10 $20 \%{ }^{31-33}$ The overall postoperative mortality in patients operated for benign lesions or liver metastasis in our institution is $2 \% .{ }^{34}$ In addition, none of the patients included in this study had undergone PVE. In some patients who developed postoperative liver failure, PVE would be indicated in retrospect; however, in these patients, the performed resection was larger than anticipated because of unexpected intraoperative findings. Patients included in this study may be different from patient populations in other clinical practices in which most patients have noncompromised livers. However, the fact that postoperative morbidity and mortality were considerable did add necessary power to the study in which risk assessment was the primary goal. Further research is, however, warranted for subgroup analysis of different patient populations.

The main advantage of HBS lies in the fact that liver function is measured, taking into account the presence of underlying parenchymal liver disease. Hence, one cutoff value for the prediction of liver failure suffices in all possible patients regardless of the quality of the liver parenchyma. In contrast, volumetric assessment of the FRL
Table 6 Overview of the Results of the Three Different Preoperative Tests in Patients with Liver Failure

The marked values indicate a false negative result of the test

\begin{tabular}{llccc}
\hline & Liver parenchyma & FRL-F $\left(\% / \mathrm{min} / \mathrm{m}^{2}\right)$ & \%FRL-V (\%) & sFRL (\%) \\
\hline 1 & Normal & 2.17 & $\mathbf{4 6}$ & $\mathbf{5 7}$ \\
2 & Compromised & 2.52 & 38 & 24 \\
3 & Compromised & 2.67 & 22 & 38 \\
4 & Compromised & 1.56 & 20 & 23 \\
5 & Compromised & 2.22 & 32 & 31 \\
6 & Compromised & 1.41 & 29 & $\mathbf{4 1}$ \\
7 & Compromised & 2.17 & 24 & 25 \\
8 & Compromised & 1.51 & 16 & 19 \\
9 & Compromised & $\mathbf{3 . 3 6}$ & $\mathbf{8 8}$ & $\mathbf{1 0 1}$ \\
\hline
\end{tabular}


requires two distinct cutoff values for patients with a compromised or noncompromised liver, assuming that the quality of the liver parenchyma is known. Especially in patients with uncertain quality of liver parenchyma, preoperative HBS is therefore of more value than \%FRL$\mathrm{V}$ or sFRL. The results of our study have led us to use HBS routinely, in addition to $\mathrm{CT}$ volumetry, in all patients considered for major liver resection. Preoperative PVE is performed when FRL-F is lower than $2.69 \% / \mathrm{min} / \mathrm{m}^{2}$ or $\%$ FRL-V is less than $30 \%$. Although around $40 \%$ of these patients will not develop liver failure, the risk of a potentially lethal complication outweighs the relatively low complication rate observed after PVE. ${ }^{35}$

\section{Conclusion}

HBS is a simple technique that can be implemented in every hospital with a nuclear medicine department. It is a valuable technique to estimate the risk of postoperative liver failure in high-risk patients undergoing major liver resection. Especially in patients with uncertain quality of the liver parenchyma, ${ }^{99 \mathrm{~m}} \mathrm{Tc}-\mathrm{mebrofenin} \mathrm{HBS}$ is of more value than $\mathrm{CT}$ volumetry since only one cutoff value can be used in both normal and compromised livers. Therefore, additional HBS can improve risk assessment in patients requiring extensive liver resection.

Open Access This article is distributed under the terms of the Creative Commons Attribution Noncommercial License which permits any noncommercial use, distribution, and reproduction in any medium, provided the original author(s) and source are credited.

\section{References}

1. Shirabe K, Shimada M, Gion T, Hasegawa H, Takenaka K, Utsunomiya T, Sugimachi K. Postoperative liver failure after major hepatic resection for hepatocellular carcinoma in the modern era with special reference to remnant liver volume. J Am Coll Surg 1999;188:304-309.

2. Kubota K, Makuuchi M, Kusaka K, Kobayashi T, Miki K, Hasegawa K, Harihara Y, Takayama T. Measurement of liver volume and hepatic functional reserve as a guide to decisionmaking in resectional surgery for hepatic tumors. Hepatology 1997;26:1176-1181.

3. Shoup M, Gonen M, D'Angelica M, Jarnagin WR, DeMatteo RP, Schwartz LH, Tuorto S, Blumgart LH, Fong Y. Volumetric analysis predicts hepatic dysfunction in patients undergoing major liver resection. J Gastrointest Surg 2003;7:325-330.

4. Vauthey JN, Chaoui A, Do KA, Bilimoria MM, Fenstermacher MJ, Charnsangavej C, Hicks M, Alsfasser G, Lauwers G, Hawkins IF, Caridi J. Standardized measurement of the future liver remnant prior to extended liver resection: methodology and clinical associations. Surgery 2000;127:512-519.
5. Abdalla EK, Hicks ME, Vauthey JN. Portal vein embolization: rationale, technique and future prospects. Br J Surg 2001;88: $165-175$.

6. Vauthey JN, Abdalla EK, Doherty DA, Gertsch P, Fenstermacher MJ, Loyer EM, Lerut J, Materne R, Wang X, Encarnacion A, Herron D, Mathey C, Ferrari G, Charnsangavej C, Do KA, Denys A. Body surface area and body weight predict total liver volume in Western adults. Liver Transpl 2002;8:233-240.

7. Abdalla EK, Barnett CC, Doherty D, Curley SA, Vauthey JN. Extended hepatectomy in patients with hepatobiliary malignancies with and without preoperative portal vein embolization. Arch Surg 2002;137:675-680.

8. Schindl MJ, Redhead DN, Fearon KC, Garden OJ, Wigmore SJ. The value of residual liver volume as a predictor of hepatic dysfunction and infection after major liver resection. Gut 2005;54:289-296.

9. Yigitler C, Farges O, Kianmanesh R, Regimbeau JM, Abdalla EK, Belghiti J. The small remnant liver after major liver resection: how common and how relevant? Liver Transpl 2003;9:S18-S25.

10. Clavien PA, Emond J, Vauthey JN, Belghiti J, Chari RS, Strasberg SM. Protection of the liver during hepatic surgery. J Gastrointest Surg 2004;8:313-327.

11. Ratziu V, Charlotte F, Heurtier A, Gombert S, Giral P, Bruckert E, Grimaldi A, Capron F, Poynard T. Sampling variability of liver biopsy in nonalcoholic fatty liver disease. Gastroenterology 2005;128:1898-1906.

12. Lindor KD, Bru C, Jorgensen RA, Rakela J, Bordas JM, Gross JB, Rodes J, McGill DB, Reading CC, James EM, Charboneau JW, Ludwig J, Batts KP, Zinsmeister AR. The role of ultrasonography and automatic-needle biopsy in outpatient percutaneous liver biopsy. Hepatology 1996;23:1079-1083.

13. McGill DB, Rakela J, Zinsmeister AR, Ott BJ. A 21-year experience with major hemorrhage after percutaneous liver biopsy. Gastroenterology 1990;99:1396-1400.

14. Bennink RJ, Dinant S, Erdogan D, Heijnen BH, Straatsburg IH, van Vliet AK, van Gulik TM. Preoperative assessment of postoperative remnant liver function using hepatobiliary scintigraphy. J Nucl Med 2004;45:965-971.

15. Erdogan D, Heijnen BH, Bennink RJ, Kok M, Dinant S, Straatsburg IH, Gouma DJ, van Gulik TM. Preoperative assessment of liver function: a comparison of $99 \mathrm{mTc}-$ mebrofenin scintigraphy with indocyanine green clearance test. Liver Int 2004;24:117-123.

16. Krishnamurthy S, Krishnamurthy GT. Technetium-99miminodiacetic acid organic anions: review of biokinetics and clinical application in hepatology. Hepatology 1989;9:139-153.

17. Dinant S, de Graaf W, Verwer BJ, Bennink RJ, van Lienden KP, Gouma DJ, van Vliet AK, van Gulik TM. Risk assessment of posthepatectomy liver failure using hepatobiliary scintigraphy and CT volumetry. J Nucl Med 2007;48:685-692.

18. Dindo D, Demartines N, Clavien PA. Classification of surgical complications: a new proposal with evaluation in a cohort of 6336 patients and results of a survey. Ann Surg 2004;240:205-213.

19. Balzan S, Belghiti J, Farges O, Ogata S, Sauvanet A, Delefosse D, Durand F. The "50-50 criteria" on postoperative day 5: an accurate predictor of liver failure and death after hepatectomy. Ann Surg 2005;242:824-828. discussion.

20. Ekman M, Fjalling M, Holmberg S, Person H. IODIDA clearance rate: a method for measuring hepatocyte uptake function. Transplant Proc 1992;24:387-388.

21. Makuuchi M, Thai BL, Takayasu K, Takayama T, Kosuge T, Gunven P, Yamazaki S, Hasegawa H, Ozaki H. Preoperative portal embolization to increase safety of major hepatectomy for hilar bile duct carcinoma: a preliminary report. Surgery 1990;107:521-527. 
22. Nagino M, Nimura Y, Kamiya J, Kondo S, Uesaka K, Kin Y, Hayakawa N, Yamamoto $\mathrm{H}$. Changes in hepatic lobe volume in biliary tract cancer patients after right portal vein embolization. Hepatology 1995;21:434-439.

23. Azoulay D, Castaing D, Krissat J, Smail A, Hargreaves GM, Lemoine A, Emile JF, Bismuth H. Percutaneous portal vein embolization increases the feasibility and safety of major liver resection for hepatocellular carcinoma in injured liver. Ann Surg 2000;232:665-672.

24. Azoulay D, Castaing D, Smail A, Adam R, Cailliez V, Laurent A, Lemoine A, Bismuth $H$. Resection of nonresectable liver metastases from colorectal cancer after percutaneous portal vein embolization. Ann Surg 2000;231:480-486.

25. Lau H, Man K, Fan ST, Yu WC, Lo CM, Wong J. Evaluation of preoperative hepatic function in patients with hepatocellular carcinoma undergoing hepatectomy. Br J Surg 1997;84:12551259.

26. Redaelli CA, Dufour JF, Wagner M, Schilling M, Husler J, Krahenbuhl L, Buchler MW, Reichen J. Preoperative galactose elimination capacity predicts complications and survival after hepatic resection. Ann Surg 2002;235:77-85.

27. Fujioka H, Kawashita Y, Kamohara Y, Yamashita A, Mizoe A, Yamaguchi J, Azuma T, Furui J, Kanematsu T. Utility of technetium-99m-labeled-galactosyl human serum albumin scintigraphy for estimating the hepatic functional reserve. J Clin Gastroenterol 1999;28:329-333.

28. Kim YK, Nakano H, Yamaguchi M, Kumada K, Takeuchi S, Kitamura N, Takahashi H, Hasebe S, Midorikawa T, Sanada Y. Prediction of postoperative decompensated liver function by technetium-99m galactosyl-human serum albumin liver scintigra- phy in patients with hepatocellular carcinoma complicating chronic liver disease. Br J Surg 1997;84:793-796.

29. Satoh K, Yamamoto Y, Nishiyama Y, Wakabayashi H, Ohkawa M. 99mTc-GSA liver dynamic SPECT for the preoperative assessment of hepatectomy. Ann Nucl Med 2003;17:61-67.

30. Nanashima A, Yamaguchi $\mathrm{H}$, Shibasaki S, Morino S, Ide N, Takeshita H, Sawai T, Nakagoe T, Nagayasu T, Ogawa Y. Relationship between indocyanine green test and technetium$99 \mathrm{~m}$ galactosyl serum albumin scintigraphy in patients scheduled for hepatectomy: clinical evaluation and patient outcome. Hepatol Res 2004;28:184-190.

31. Jarnagin WR, Fong Y, DeMatteo RP, Gonen M, Burke EC, Bodniewicz BJ, Youssef BM, Klimstra D, Blumgart LH. Staging, resectability, and outcome in 225 patients with hilar cholangiocarcinoma. Ann Surg 2001;234:507-517.

32. Dinant S, Gerhards MF, Busch ORC, Obertop H, Gouma DJ, van Gulik TM. The importance of complete excision of the caudate lobe in resection of hilar cholangiocarcinoma. HPB 2005;7:263267.

33. Belghiti J, Hiramatsu K, Benoist S, Massault P, Sauvanet A, Farges O. Seven hundred forty-seven hepatectomies in the 1990s: an update to evaluate the actual risk of liver resection. J Am Coll Surg 2000;191:38-46.

34. Erdogan D, Busch OR, Gouma DJ, van Gulik TM. Morbidity and mortality after liver resection for benign and malignant hepatobiliary lesions. Liver Int 2008;29:175-180.

35. Giraudo G, Greget M, Oussoultzoglou E, Rosso E, Bachellier P, Jaeck D. Preoperative contralateral portal vein embolization before major hepatic resection is a safe and efficient procedure: a large single institution experience. Surgery 2008;143:476-482. 